\title{
Options trading strategy based on ARIMA forecasting
}

\author{
Pierre Rostan
}

Department of Business, American University of Afghanistan, Kabul, Afghanistan

\author{
Alexandra Rostan \\ American University of Afghanistan, Kabul, Afghanistan, and \\ Mohammad Nurunnabi \\ Department of Accounting, Prince Sultan University, Riyadh, Saudi Arabia
}

\begin{abstract}
Purpose - The purpose of this paper is to illustrate a profitable and original index options trading strategy.

Design/methodology/approach - The methodology is based on auto regressive integrated moving average (ARIMA) forecasting of the S\&P 500 index and the strategy is tested on a large database of S\&P 500 Composite index options and benchmarked to the generalized auto regressive conditional heteroscedastic (GARCH) model. The forecasts validate a set of criteria as follows: the first criterion checks if the forecasted index is greater or lower than the option strike price and the second criterion if the option premium is underpriced or overpriced. A buy or sell and hold strategy is finally implemented.

Findings - The paper demonstrates the valuable contribution of this option trading strategy when trading call and put index options. It especially demonstrates that the ARIMA forecasting method is a valid method for forecasting the S\&P 500 Composite index and is superior to the GARCH model in the context of an application to index options trading.

Originality/value - The strategy was applied in the aftermath of the 2008 credit crisis over 60 months when the volatility index (VIX) was experiencing a downtrend. The strategy was successful with puts and calls traded on the USA market. The strategy may have a different outcome in a different economic and regional context.
\end{abstract}

Keywords Index options, Trading strategy, Options strategy, ARIMA model, GARCH model, Forecasting

Paper type Research paper

\section{Introduction}

Options securities have been traded using a variety of strategies with more or less success. Most of the strategies applied by traders are based on expectations regarding most

(C) Pierre Rostan, Alexandra Rostan and Mohammad Nurunnabi. Published in PSU Research Review. Published by Emerald Publishing Limited. This article is published under the Creative Commons Attribution (CC BY 4.0) licence. Anyone may reproduce, distribute, translate and create derivative works of this article (for both commercial and non-commercial purposes), subject to full attribution to the original publication and authors. The full terms of this licence may be seen at http:// creativecommons.org/licences/by/4.0/legalcode

Conflict of interest statement: Disclosure of potential conflicts of interest: All authors declare that no potential conflict of interest exists. 
PRR

4,2

\section{2}

commonly the trend of the underlying asset price and the level of the volatility of returns of the asset price. These expectations may either rely on:

(1) their intuition;

(2) their access to information. For example, Hsieh and He (2014) found that foreign institutional investors in the Taiwan market are the most informed traders, with their predictive ability being more apparent in a downward market. They tend to use out-of-the-money options to achieve high leverage, along with medium-term options to obtain large delta exposure and low theta risk, whilst also sacrificing liquidity by forgoing the use of short-term options; and

(3) these expectations may finally be obtained from fundamental, technical or econometric models. This paper presents an original option trading strategy based on the well-known auto regressive integrated moving average (ARIMA) econometric model.

ARIMA $(1,1,1)$ is benchmarked to the generalized auto regressive conditional heteroscedastic $(\mathrm{GARCH})(1,1)$ model.

Section 2 reviews the literature on option strategies. Section 3 explains the methodology underlying the options trading strategy proposed in this paper. Section 4 presents and discusses the results. Section 5 wraps up the main findings of the paper.

\section{Literature review}

Options are traded over-the-counter (OTC) through a dealer network or on centralized exchange markets. OTC markets are less transparent and operate with fewer rules than do exchanges. OTC markets are mostly accessible to institutional investors and companies. Market participants of the options exchange market include professional traders working for proprietary trading firms and for institutional investors such as banks, investment companies, insurance companies or pension funds. In the past two decades, easy access of retail investors to the options exchange market offered by brokerage firms on internet have added myriads of individuals to the number of options market participants. Bauer et al. (2009) have shown that the profile of these individual investors carries some similarities: many of them are gamblers looking for a new source of entertainment with the trade of options providing a huge leverage, often leading to much larger losses than the ones from equity trading. The reasons of their poor performance are attributed to a lack of market timing due to overreaction to past stock market returns, high trading costs and the profile of gamblers that usually lack discipline and rational behavior. This addition of unskilled investors is obviously a benefit for the options exchange market with an increased market depth because of higher trading volumes, higher open interests and tighter spreads. It is also beneficial to professional traders who see their revenues growing by placing opposite trades to the ones of individual investors. As a result, Fahlenbrach and Sandås (2010) found that options strategies are used both by traders who possess non-public information about future volatility and by uninformed speculators who appear to follow unprofitable trend chasing strategies.

Options traders implement a variety of strategies, the most common strategies rely on the expectations of two parameters, the trend of the underlying asset price (bull, bear or neutral market) and the volatility of the returns of the underlying asset price (increasing, decreasing or neutral volatility). In this two-dimension framework, traders will apply long call or long strap if they expect a bull market and an increasing volatility, long straddle, short butterfly or long strangle if they expect a neutral market and an increasing volatility, short straddle, long 
butterfly or short strangle if they expect a neutral market and a decreasing volatility, etc. These strategies are extensively explained in manuals specialized in financial derivatives (Hull, 2017), options trading books (Bittman, 1998; Ansbacher, 2000; Trester, 2003; McMillan, 2004 or Kraus, 2010). Exchanges specialized in derivatives also offer training on options trading such as the Chicago board of options exchange (CBOE) (CBOE seminars, 2017) or the Montreal Exchange seminars (2017). In addition, Chaput and Ederington (2003) examined option spread and combination trading, identifying, which positions are commonly traded (spreads, straddles, strangles) and reviewing the reasons for trading combinations.

Yang et al. (2019) identifies the relationship that exists between volatility trading and investors' types. By analyzing intraday volatility information trading according to the demand for options, these authors determine the types of investors that are informed about future spot market volatility and conduct volatility information trading in a highly liquid options market.

Among the studies assessing the performance of options strategies, Guo (2000) showed that after accounting for transaction costs, using the implied stochastic volatility regression method or the GARCH method to forecast the volatility of foreign exchange rates, both delta-neutral and straddle trading strategies involving currency options lead to observed profits not significantly different from zero.

Over a decade, Hemler and Miller (2013) analyzed options-based investment strategies vs a buy-and-hold strategy in the underlying stock for 10 stocks. They found that based on monthly returns from five strategies, covered combination and covered call strategies generally outperform the long stock strategy, which in turn generally outperforms the collar and protective put strategies regardless of the performance measure considered (Sharpe ratio, Jensen's alpha, Treynor ratio or Sortino ratio).

Identifying profitable options strategies in the literature, Maris et al. (2007), using volatility forecasts obtained from the combination of an artificial neural network (a two-layer), a shortterm oriented naïve method and a mid-term oriented moving sverage of 13 -week-model, they ended up with a profitable trading strategy with options on FTSE/ASE 20 index. Sheu and Wei (2011) introduced an effective option trading strategy based on superior volatility forecasts using actual option price data from the Taiwan stock market. They found that, implementing a long or short straddle based on the 60-day in-sample-period volatility forecasting, 15 days before options' final settlement day, achieved a significant return. Simmons (2012) forecasted the ASX 200 index with a differential evolutionary algorithm and applied an option trading strategy based on forecasts that shown to perform better than a buy and hold strategy. Using a volatility forecasting model derived from three components of the financial statements, earnings yield volatility, change in market to book premium volatility and the covariance of the earnings yield with the change in market to book premium, Sridharan (2015) implemented a profitable option-based trading strategy. Simon (2017) identified profitable VIX option trading strategies based on buying VIX options to exploit the tendency of VIX futures to rise and fall when the VIX futures curve is in backwardation and in contango, respectively and the tendency of VIX futures ex ante volatility premiums to spike and then revert to more typical levels. Hong et al. (2018) examined the profitability of volatility trading on S\&P 500 equity index options in time-varying market conditions, with a particular focus on evaluating the authenticity of risk-adjusted returns. While significant profits are available on strategies that involve writing put options, their findings cast doubt on whether these profits can be genuinely attained in practice. After bid-ask spreads are included, they find that the profitability is significantly reduced.

This paper introduces a robust options strategy based on ARIMA forecasting and a predefined set of criteria. The strategy is not left to the appreciation or intuition of the 
PRR

4,2

market participants but relies on a systematic methodology explained in the next chapter.

\section{Methodology}

The objective of the paper is to validate an original options trading strategy based on ARIMA forecasting. The strategy is tested on S\&P 500 index European call and put options traded on the Chicago Mercantile Exchange (CME) over 60 months from January 30, 2009 to December 30, 2013. The S\&P 500 index measures the stock performance of 500 listed large cap stocks of the USA. From the database, premiums quotations lower than 50 cents are removed, as the corresponding options are more subject to mispricing. After filtration, we gather 43,014 quotations of calls and 38,784 quotations of puts for a total of 81,798 option premiums. The moneyness of puts and calls ranges from deep out of the money to deep in the money with strike prices spreading from 100 to 3,000 and maturities from very short to very long-term, extending from 21 days to 627 days.

Figure 1 illustrates 4,826 daily values of the S\&P 500 Composite index from December 11, 1996 to June 19, 2015. Starting at the vertical dash line on January 30, 2009 is the forecasting period extending to June 19, 2015. During this period, the global financial system was battling a post credit crisis following the bankruptcy of Lehman brothers on September 2008, the fourth largest US investment bank at this time. This bankruptcy was the largest in US history. The threat of a domino effect on other big names of the banking sector obliged central banks in the US and in Europe to bail out some banks. The credit was frozen. To avoid recession, central banks implemented a zero-rate policy through quantitative easing. Bond yields falling to record low forced investors to pour their money into the equity market sector propping up the S\&P 500 Composite index to historical highs. The S\&P 500 Composite index observed in Figure 1 just after the vertical dash line on January 30, 2009 initiated an uptrend, which extended over the period and may be identified as a submartingale. The augmented Dickey-Fuller test is applied to the whole sample of 4,826 prices and to the sub-sample from December 11, 1996 to January 30, 2009 (3,168 data on the left hand-side of the vertical dot line). It identifies a unit root that confirms the nonstationary of the two samples under scrutiny.

The option trading strategy is based on ARIMA forecasting. ARIMA $(p, d, q)$, process that fits historical data to generate non stationary series that are integrated of order $d$. A non-stationary integrated of order $d$ process is transformed into stationary process by taking $d$ differences. The AR term refers to auto regressive (AR) and involves regressing the variable on its own lagged past values and the MA term refers to moving average (MR), involving modeling the error term as a linear combination of error terms. The choice of the ARIMA $(1,1,1)$ forecasting model is explained at Step 1.

We applied the four-step methodology illustrated by Figure 2 to the time series of historical daily S\&P 500 composite index prices from December 11, 1996 to June 19, 2015 (4,826 data).

\subsection{Step 1: identifying the best auto regressive integrated moving average model}

To choose the ARIMA model that best fits the S\&P 500 index data, we identify the ARMA lags $p$ and $q$ by applying the Bayesian information criterion (BIC) to the S\&P Composite index time series. For this purpose, we estimate several models with different $p$ and $q$ values. For each estimated model, we compute the log likelihood objective function value. Then, we input the log likelihood value to compute the BIC measure of fit, which penalizes for complexity. This methodology is implemented in Matlab using the econometrics toolbox. 


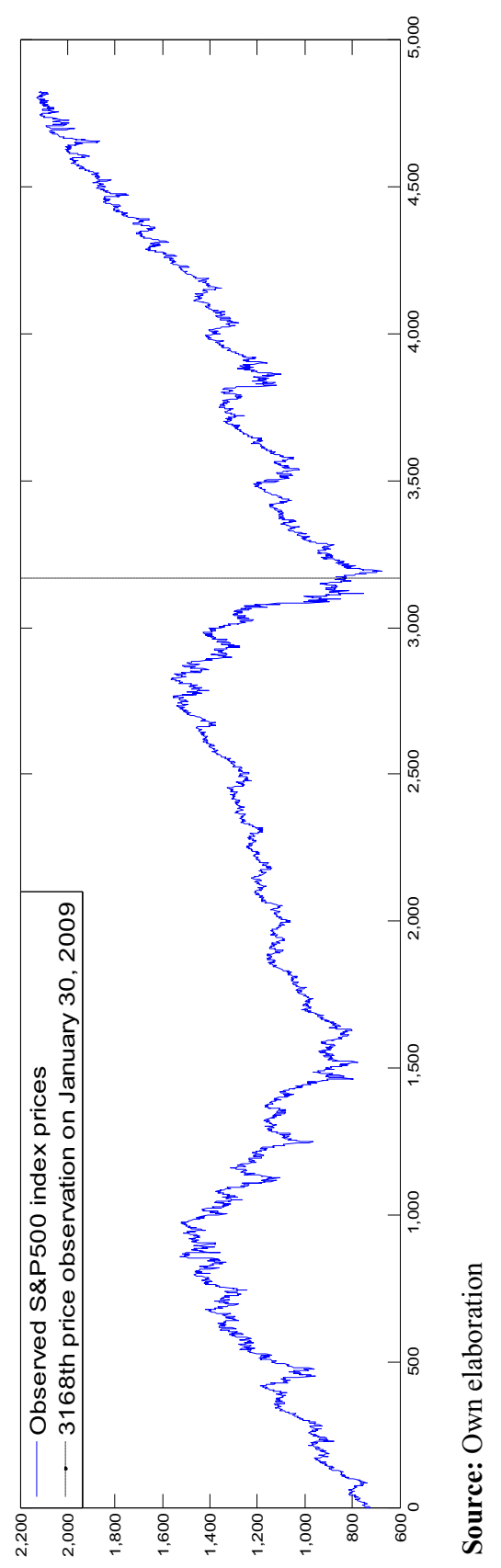

Options trading strategy

115

Figure 1. Time series of historical daily S\&P 500 Composite index prices from December 11, 1996 to June 19, 2015 (4,826 data) 


\section{PRR}

4,2

116

Figure 2.

Flowchart of the research methodology

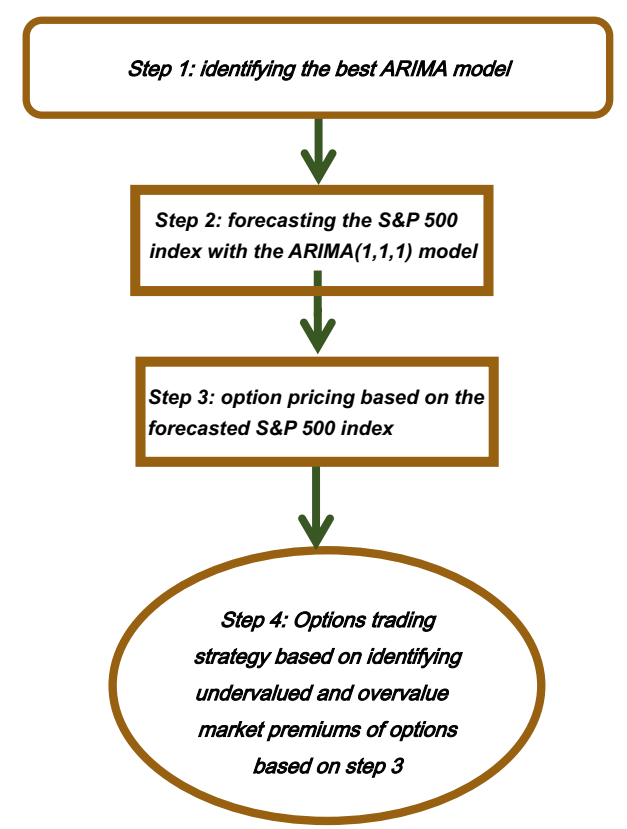

In Figure 3, we plot the sample autocorrelation function (ACF) and the partial autocorrelation function (PACF) of the S\&P Composite index time series illustrated in Figure 1 from December 11, 1996 to January 30, 2009 (3,168 data on the left-hand side of the vertical dot line).

The sample ACF decays slowly, which is consistent with an ARMA model. We can have a rough idea of the ARMA lags by looking at the PACF. It appears than no more than three $\mathrm{AR}$ or MA terms are required.

To formally identify the ARMA lags, we fit several models with different lag choices, making the degree of differencing (i.e. the "I" of ARIMA) varying from 0 to 2 . We fit all combinations of ARMA $(p, q)$ for $p=1, \ldots, 4$ and $q=1, \ldots, 4$ (a total of 16 models per degree of differencing). We store the log-likelihood objective function and number of coefficients for each fitted model. We calculate the BIC for each fitted model. We obtain the following two output BIC matrices for the first and second-order differencing:

- no differencing: no output BIC matrix possible, as the model is unstable.

- first order differencing:

$$
\begin{array}{llll}
1.0 \mathrm{e}+04^{*} & & \\
2.5922 & 2.5926 & 2.5931 & 2.5931 \\
2.5927 & 2.5929 & 2.5932 & 2.5926 \\
2.5929 & 2.5932 & 2.5931 & 2.5925 \\
2.5931 & 2.5924 & 2.5933 & 2.5934
\end{array}
$$

- second-order differencing: 

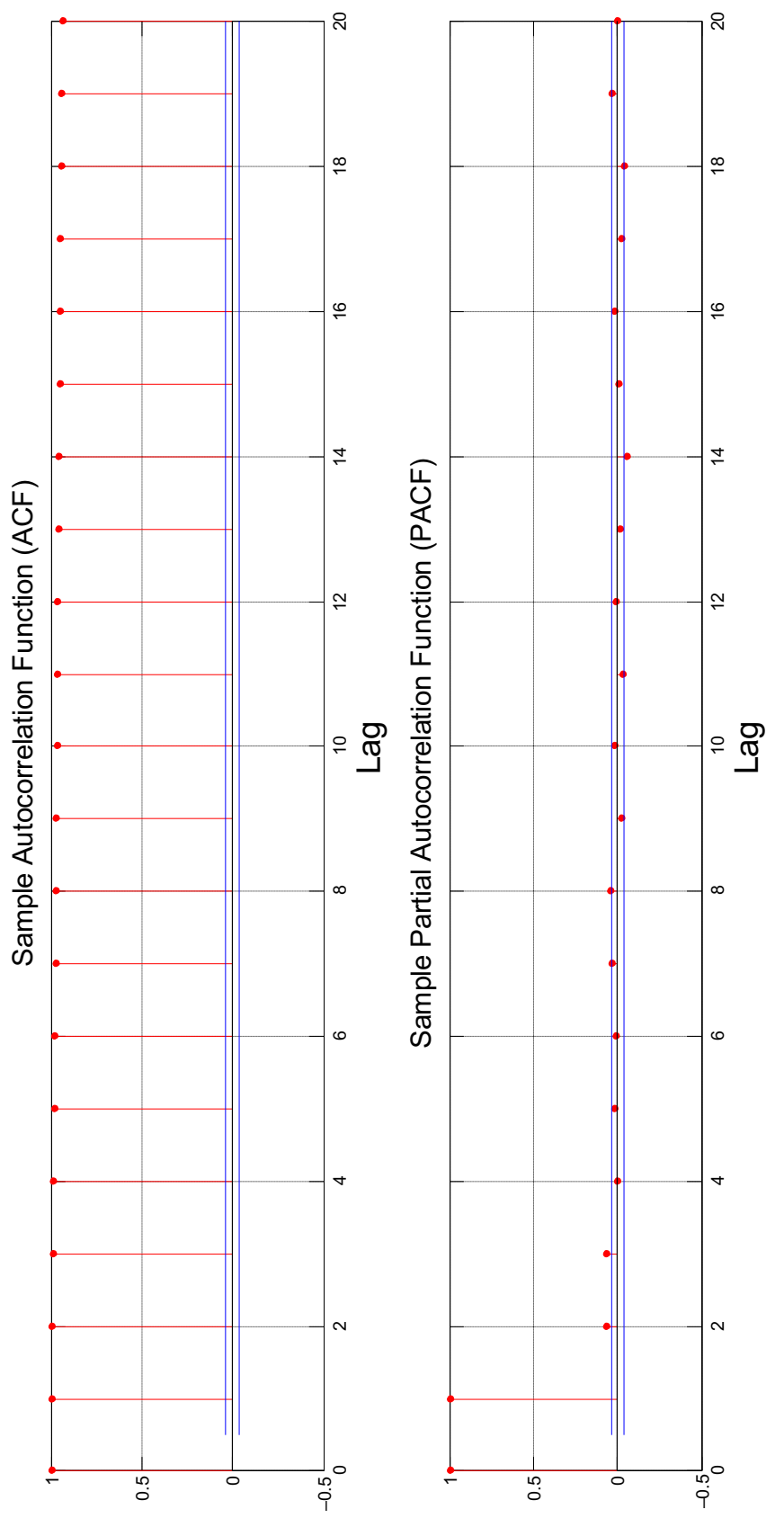

Options trading strategy

Figure 3. sample ACF and

PACF for the historical daily S\&P 500 Composite index time series from December 11, 1996 to January 30, 2009

(3,168 data) 


$\begin{array}{lllll}\text { PRR } & 1.0 \mathrm{e}+04 * & & \\ 4,2 & 2.5983 & 2.5983 & 2.5969 & 2.5964 \\ & 2.5974 & 2.5968 & 2.5972 & 2.5957 \\ & 2.5978 & 2.5962 & 2.5957 & 2.5962 \\ & 2.5980 & 2.5967 & 2.5952 & 2.5959\end{array}$

\section{8}

In the two output BIC matrices above, the rows correspond to the AR degree $(p)$ and the columns correspond to the MA degree $(q)$. The best value in the first BIC matrix (first-order differencing) is the smallest BIC value equal to 25,922 in the $(1,1)$ position. The second output BIC matrix (second-order differencing) contains all BIC values higher than the values of the first matrix. This observation suggests the optimality of the first order differencing. These combined observations converge to the choice of an ARIMA $(1,1,1)$ model as the most reliable model for forecasting the S\&P 500 composite index. To implement our strategy over 60 months, we calibrate every month the ARIMA $(1,1,1)$ model with the daily historical sample of S\&P 500 composite index starting on December 11, 1996 and ending the day prior to the forecasting period. For example, on January 30, 2009, the computed ARIMA $(1,1,1)$ model parameters are presented in Table 1 .

\subsection{Step 2: forecasting the S\&P 500 composite index with the auto regressive integrated moving average $(1,1,1)$ model}

We forecast the daily time series of the S\&P 500 Composite index from February 2, 2009 to June 19, 2015 (1,658 business days). Over a period of 60 months (from January 30, 2009 to December 31, 2013), we choose each month a forecasting period that matches the longest maturity of the S\&P 500 composite index calls and puts that trade on CME on this month. Table 2 gathers the forecasting periods over 61 months.

\subsection{Step 3: option pricing based on the forecasted S\&P 500 composite index}

The S\&P 500 Composite index price $S_{T}$ forecasted at option maturity $T$ is plugged in equation (1), which compute today's option price $C_{O}$ :

$$
\begin{aligned}
& C_{0}=e^{-r T}\left[\left(S_{T}-X\right)^{+}\right] \text {for a call option } \\
& C_{0}=e^{-r T}\left[\left(X-S_{T}\right)^{+}\right] \text {for } a \text { put option }
\end{aligned}
$$

Table 1.

Parameters of the ARIMA $(1,1,1)$ model on January 30 , 2009
$\operatorname{ARIMA}(1,1,1)$ model:

Conditional probability distribution: Gaussian

\begin{tabular}{lccc} 
Parameter & Value & Standard error & $t$-statistic \\
\hline Constant & 0.0123731 & 0.0939195 & 0.131742 \\
AR $\{1\}$ & 0.590244 & 0.0757896 & 7.78793 \\
MA $\{1\}$ & -0.668043 & 0.0684585 & -9.75836 \\
Variance & 208.54 & 2.84668 & 73.2571
\end{tabular}

Source: Own elaboration 


\begin{tabular}{|c|c|c|c|c|}
\hline $\begin{array}{l}\text { Dates of option quotations } \\
\text { over } 61 \text { months }\end{array}$ & $\begin{array}{l}\text { No. of daily } \\
\text { forecasted data with } \\
\text { ARIMA }(1,1,1)\end{array}$ & $\begin{array}{l}\text { Dates of options quotations } \\
\text { over } 61 \text { months }\end{array}$ & $\begin{array}{l}\text { No. of daily } \\
\text { forecasted data with } \\
\text { ARIMA }(1,1,1)\end{array}$ & $\begin{array}{l}\text { Options } \\
\text { trading } \\
\text { strategy }\end{array}$ \\
\hline January 30, 2009 & 750 & July 29, 2011 & 645 & \\
\hline February 27,2009 & 730 & August 31, 2011 & 622 & \\
\hline March 31, 2009 & 708 & September 30, 2011 & 600 & \\
\hline April 30, 2009 & 686 & October 31, 2011 & 579 & 119 \\
\hline May 29, 2009 & 665 & November 30, 2011 & 557 & \\
\hline June 30, 2009 & 643 & December 30, 2011 & 535 & \\
\hline July 31, 2009 & 620 & January 31, 2012 & 513 & \\
\hline August 31, 2009 & 599 & February 29, 2012 & 492 & \\
\hline September 30, 2009 & 577 & March 30, 2012 & 470 & \\
\hline October 30, 2009 & 555 & April 30, 2012 & 449 & \\
\hline November 30, 2009 & 534 & May 31, 2012 & 426 & \\
\hline December 31, 2009 & 776 & June 29,2012 & 405 & \\
\hline January 29, 2010 & 755 & July 31, 2012 & 408 & \\
\hline February 26, 2010 & 735 & August 31, 2012 & 385 & \\
\hline March 31, 2010 & 712 & September 28, 2012 & 365 & \\
\hline April 30, 2010 & 690 & October 31, 2012 & 342 & \\
\hline May 31, 2010 & 669 & November 30, 2012 & 320 & \\
\hline June 30, 2010 & 647 & December 31, 2012 & 299 & \\
\hline July 30,2010 & 625 & January 31,2013 & 508 & \\
\hline August 31, 2010 & 603 & February 28,2013 & 488 & \\
\hline September 30, 2010 & 581 & March 29, 2013 & 467 & \\
\hline October 29, 2010 & 560 & April 30, 2013 & 445 & \\
\hline November 30,2010 & 538 & May 31, 2013 & 422 & \\
\hline December 31, 2010 & 795 & June 28, 2013 & 402 & \\
\hline January 31, 2011 & 774 & July 31, 2013 & 379 & \\
\hline February 28,2011 & 754 & August 30, 2013 & 357 & \\
\hline March 31, 2011 & 731 & September 30, 2013 & 442 & \\
\hline April 29, 2011 & 710 & October 31, 2013 & 419 & \\
\hline May 31, 2011 & 688 & November 29,2013 & 398 & 1able 2. \\
\hline June 30,2011 & 666 & December 31, 2013 & 376 & Adjusting the \\
\hline July 29, 2011 & 645 & - & - & forecasting period \\
\hline Source: Own elaboration & & & & option quotations \\
\hline
\end{tabular}

With $X=$ strike price of the option and $r$ the US eurodollar deposit one-month bid observed at the time of option pricing, used as proxy of the risk-free rate. We price 43,014 calls and 38,784 puts for a total of 81,798 options.

\subsection{Step 4: options trading strategy}

We identify undervalued and overvalued market premiums of options based on Step 3. When the value of the option (call or put) computed with equation (6) is lower (higher) than the option market premium, the option is overvalued (undervalued).

We apply the option trading strategy presented in Table 3 for 60 months from January 2009 to December 2013. We add transaction costs (commission, regulatory, transaction and clearing fees) of $\$ 1.10$ per traded option either long or short. In addition, as the multiplier of S\&P 500 index options is $\$ 100$ and premium quotes are stated in 


\begin{tabular}{lll}
\hline Option type & Criterion 1 & Criterion 2 \\
\hline Call & Forecasted $\mathrm{S}_{\mathrm{T}}>\mathrm{X}$ & $\begin{array}{l}\text { and market premium is } \\
\text { undervalued }\end{array}$ \\
Forecasted $\mathrm{S}_{\mathrm{T}}<=\mathrm{X}$ & $\begin{array}{l}\text { And market premium is } \\
\text { undervallued }\end{array}$
\end{tabular}

\section{Table 3.}

Option trading strategy. "forecasted $\mathrm{S}_{\mathrm{T}}$ " is the index price forecasted at option maturity obtained at Step 2 of the methodology. " $\mathrm{X}$ " is the exercise price of the option. "ITM" means "in-themoney"

$\begin{array}{ll}\text { Forecasted } \mathrm{S}_{\mathrm{T}}>\mathrm{X} & \begin{array}{l}\text { And market premium is } \\ \text { overvalued }\end{array}\end{array}$

Forecasted $\mathrm{S}_{\mathrm{T}}<=\mathrm{X} \quad$ And market premium is overvalued Market premium is fairly valued

Put $\quad$ Forecasted $\mathrm{S}_{\mathrm{T}}>=\mathrm{X}$ And market premium is undervalued

Market premium is fairly valued

$\begin{array}{ll}\text { Forecasted } \mathrm{S}_{\mathrm{T}}<\mathrm{X} & \begin{array}{l}\text { And market premium is } \\ \text { undervalued }\end{array} \\ \text { Forecasted } \mathrm{S}_{\mathrm{T}}>=\mathrm{X} & \begin{array}{l}\text { And market premium is } \\ \text { overvalued } \\ \text { And market premium is } \\ \text { overvalued }\end{array}\end{array}$

Source: Own elaboration
Strategy

Buy and hold to maturity - exercise at maturity if ITM; make a gain Ignore the option if the option maturity is less than or equal to a month. If not, buy the option and sell it in one month Ignore the option if the option maturity is less than or equal to a month. If not, sell the option and buy it in one month

Sell and hold to maturity - exercise at maturity if itm; incur a loss

Ignore the option

Ignore the option if the option maturity is less than or equal to a month. If not, buy the option and sell it in one month

Buy and hold to maturity - exercise at maturity if itm; make a gain

Sell and hold to maturity - exercise at maturity if itm; incur a loss

Ignore the option if the option maturity is less than or equal to a month. If not, sell the option and buy it in one month

Ignore the option

decimals, one point equals $\$ 100$. Premium quotes, profits and losses will, therefore, be multiplied by 100 . The strategy is applied every month and is rolled over 60 months. We compute the profit and loss based on 81,798 option quotes. We express the total profit of the strategy in dollar profit, profitability index, internal rate of return (IRR) and modified internal rate of return (MIRR) when available. We buy options at the Ask price and sell them at the bid price. As our database contains only mid-quotes, we apply a $6 \%$ spread below and above the mid-quote to compute, respectively, bid and ask prices.

\subsection{Step 5: benchmarking the ARIMA model}

We benchmark the ARIMA $(1,1,1)$ model to the $\operatorname{GARCH}(1,1)$ model. $\operatorname{GARCH}(p, q)$, model that fits historical data to generate nonstationary series. Auto Regressive describes a feedback mechanism by which past observations are incorporated into the present represented by the Parameter p. Heteroscedastic means that the model is able to model the variance of historical data that varies over time, represented by the Parameter q. Conditional implies dependence on recent observations from the past. The S\&P composite index forecasts obtained from the $\operatorname{GARCH}(1,1)$ model are plugged in the option trading strategy presented in Table 3.

\section{Results}

The options trading strategy presented in Table 3 is applied over a period of 60 months (from January 30, 2009 to December 31, 2013). Figure 4 illustrates 60 months of gains and 
losses and net profits of the strategy with calls and Figure 5 gains, losses and net profits with puts (Figure 5 top).

To understand the use of Table 3 , let us consider the following example.

The trader decides to implement a call option strategy if the forecasted index price at maturity of the call option $S_{T}$, is higher than the exercise price of the option $X$ and if the market premium of the option is undervalued. Based on Table 3 , the strategy is to buy the call option and to exercise it at option maturity if the option is in-the-money (ITM). The profit earned at option maturity is then discounted at time zero when the call option is purchased.

Options trading strategy

Table 4 shows the profitability of the option trading strategy based on the ARIMA $(1,1$, 1) forecasting model with call and put options with a discounted net profit, respectively, equal to $\$ 97,819,217$ and $\$ 16,180,811$ over 60 months, a profitability index, respectively, equal to 2.40 and 1.40 , a MIRR, respectively, equal to $379 \%$ and $218 \%$.

Figures 4 and 5 illustrate 60 months of gains and losses and net profits of the option trading strategy using ARIMA $(1,1,1)$ forecasts of S\&P 500 index with calls (Figure 4 ) and with puts (Figure 5 top). Figure 5 bottom illustrates the VIX index, i.e. a proxy of the volatility of the S\&P 500 index during the 60 months of the database.

The ARIMA $(1,1,1)$ model is benchmarked to the GARCH $(1,1)$ model. Table 5 shows the profitability of the option trading strategy based on the $\operatorname{GARCH}(1,1)$ forecasting model with call and put options with a discounted net profit, respectively, equal to $\$ 70,151,565$ and $\$ 23,161,345$ over 60 months, a profitability index, respectively, equal to 1.94 and 1.68 , a MIRR equal to $314 \%$ and $271 \%$.

From Tables 4 and 5, we observe that, for both option trading strategies based on ARIMA $(1,1,1)$ and on GARCH $(1,1)$ forecasting models, the overall performance measures of discounted net profit, profitability index and MIRR are always higher with call options than put options. The explanation lies on the bullish nature of the underlying S\&P 500 Composite index of the options during the period of implementation of the strategies (Figure 1). Profit is larger on calls than puts options in a bull market, as the intrinsic value of calls increases overtime while the intrinsic value of puts decreases.

The second observation is that the option trading strategy based on ARIMA $(1,1,1)$ forecasting model with calls offers a higher discounted net profit than the one based on GARCH $(1,1)$ forecasting model $(\$ 97,819,217$ vs $\$ 70,151,565)$, a higher profitability index (2.40 vs 1.94) and a higher MIRR (379\% vs $314 \%)$. We may explain this observation by the fact that the percentage of times (out of 34,990) that the call option is correctly identified as undervalued or overvalued is $64 \%$ with ARIMA $(1,1,1)$ vs $59 \%$ with $\operatorname{GARCH}(1,1)$.

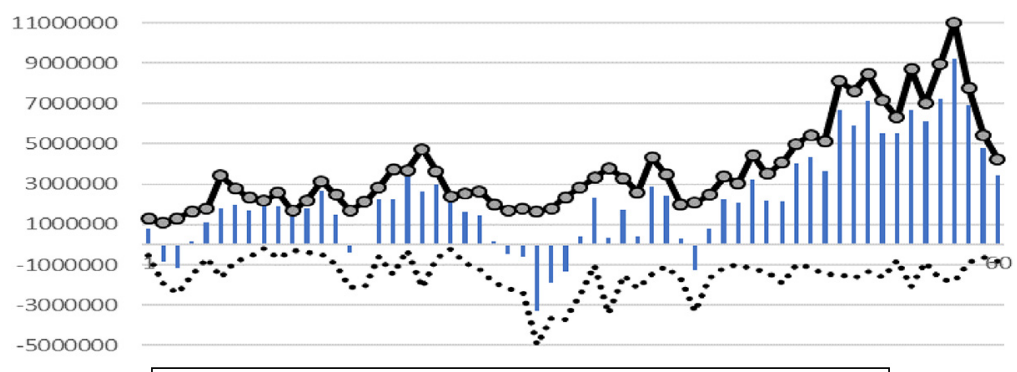

Figure 4.

60 months of gains and losses of the option trading strategy of the ARIMA $(1,1,1)$ forecasting model with calls 
PRR

4,2

122
Figures 5.

60 months of gains and losses of the option trading strategy of the $\operatorname{ARIMA}(1,1,1)$ forecasting model with puts (top) and VIX index (bottom)

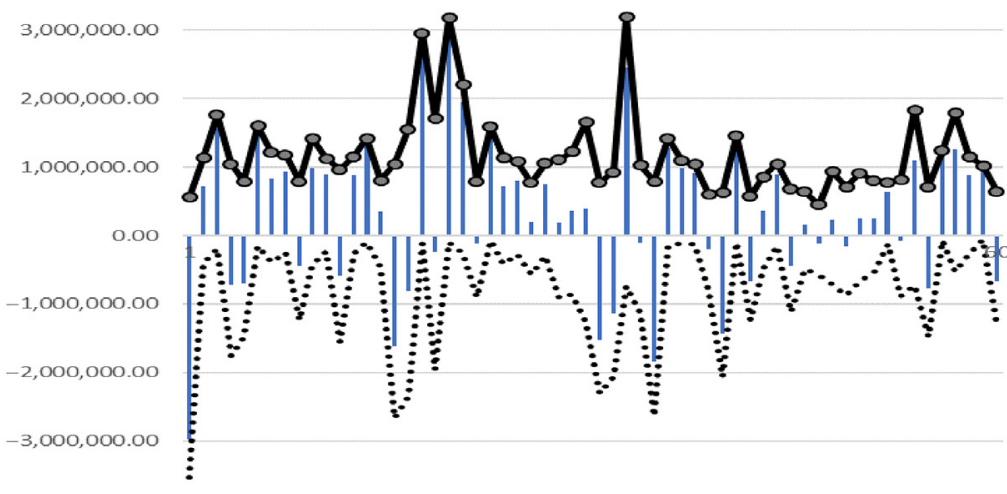

$-4,000,000.00$

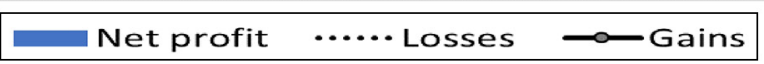

VIX index over the 60-month database

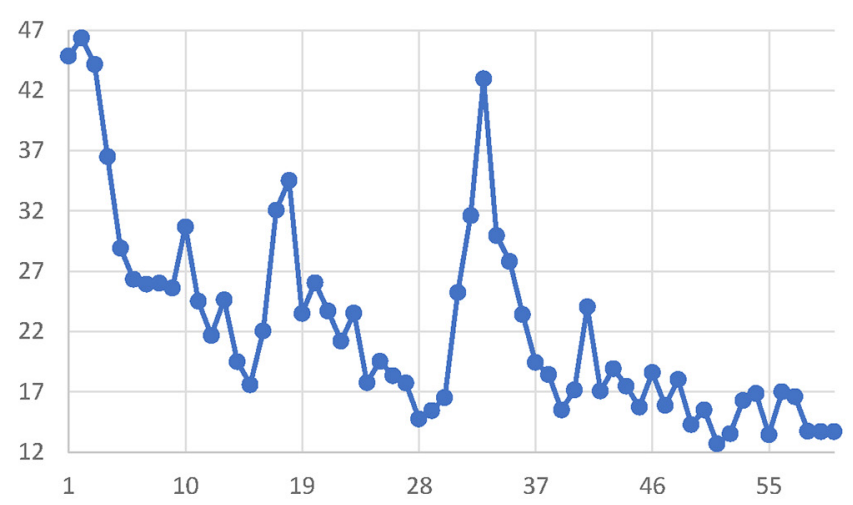

Source: Own elaboration

The third observation is that the option trading strategy based on GARCH $(1,1)$ forecasting model with puts offers a higher discounted net profit than the one based on ARIMA $(1,1,1)$ forecasting model $(\$ 23,161,345$ vs $\$ 16,180,811)$, a higher profitability index (1.68 vs 1.40$)$ and a higher MIRR (271\% vs $218 \%$ ). We may explain this observation by the fact that the percentage of times (out of 33,206) that the put option is correctly identified as undervalued or overvalued is $79 \%$ with GARCH $(1,1)$ vs $78 \%$ with ARIMA $(1,1,1)$. GARCH $(1,1)$ is a better model with puts than ARIMA $(1,1,1)$ As the profit generated with the strategy involving puts is closely related to the volatility of the S\&P 500 Composite index. Figures 5 and 7 show that the three major peaks of net profits with puts (months 18, 20 and 33) correspond to peaks in the VIX index. The VIX index is built by CBOE from the implied volatility of S\&P 500 index options and it gauges the market participants' expectation of the stock market volatility over the next 30 days. Thus, we assume that the VIX index is a good proxy of the volatility of the S\&P 500 Composite index. Our strategy with puts generates higher profit during peaks of volatility. As the $\operatorname{GARCH}(1,1)$ model incorporates a volatility 
Strategy with calls

Discounted losses (1)

Discounted gains (2)

Future gains (3)

Discounted net profit $(1)+(2)$

Profitability index (2)/|1|

IRR (APR annually compounded)

MIRR (APR annually compounded) $12 *[(3) /(1)]^{1 / 60 * 12}-1$

$\%$ of times (out of 34,990 ) the call option is correctly identified as undervalued or overvalued

Strategy with puts

Discounted losses (4)

Discounted gains (5)

Future gains (6)

Discounted net profit $(4)+(5)$

Profitability index (5)/ $|4|$

IRR (APR annually compounded)

MIRR (APR annually compounded) $12 *[(6) /(4)]^{1 / 60 * 12}-1$

$\%$ of times (out of 33,206 ) the put option is correctly identified as

undervalued or overvalued
Discount rate $=10 \%$ (APR monthly

compounded)

$-\$ 69,819,723$

$\$ 167,638,941$

$\$ 275,817,847$

$\$ 97,819,217$

2.40

N/A, NPV always positive

$379 \%$

$64 \%$

Discount rate $=10 \%$ (APR monthly compounded)

NPV $\$ 40,392,002$

$\$ 56,572,812$

$\$ 93,079,754$

$\$ 16,180,811$

1.40

$211 \%$

$218 \%$

$78 \%$

Notes: NPV = Net present value; IRR $=$ internal rate of retu; $M I R R=$ modified internal rate of return

Source: Own elaboration
Options trading strategy

Table 4.

Assessing the option trading strategy based on ARIMA (1,

1, 1) forecasting model with calls and puts, computing profitability index,

IRR, MIRR and

percentage of times the option is correctly identified as undervalued or overvalued
Strategy with calls

Discounted losses (1)

Discounted gains (2)

Future gains (3)

Discounted net profit $(1)+(2)$

Profitability index (2)/ $|1|$

IRR (APR annually compounded)

MIRR (APR annually compounded) $12 *[(3) /(1)]^{1 / 60 * 12}-1$

$\%$ of times (out of 34,990 ) the call option is correctly identified as undervalued or overvalued

Strategy with puts

Discounted losses (4)

Discounted gains (5)

Future gains (6)

Discounted net profit $(4)+(5)$

Profitability index (5)/ $|4|$

IRR (APR annually compounded)

MIRR (APR annually compounded) $12 *[(6) /(4)]^{1 / 60 * 12}-1$

$\%$ of times (out of 33,206 ) the put option is correctly identified as undervalued or overvalued

Source: Own elaboration
Discount rate $=10 \%$ (APR monthly compounded)

$-\$ 74,512,055$

$\$ 144,663,620$

$\$ 238,016,347$

$\$ 70,151,565$

1.94

N/A, NPV always positive

$314 \%$

$59 \%$

Discount rate $=10 \%$ (APR monthly compounded)

$-\$ 33,814,031$

$\$ 56,975,376$

$\$ 93,742,095$

$\$ 23,161,345$

1.68

$313 \%$

$271 \%$

$79 \%$
Table 5.

Assessing the option trading strategy based on the GARCH

$(1,1)$ forecasting model with calls and puts, computing profitability index,

IRR, MIRR and

percentage of times the option is correctly identified as undervalued or overvalued 
PRR

4,2

124

component, this model is expected to provide a better forecasting accuracy than the ARIMA $(1,1,1)$ model in period of high volatility when our strategy generates higher profit. GARCH $(1,1)$ model beats indeed ARIMA $(1,1,1)$ model in terms of profit during periods of high volatility.

Figures 6 and 7 illustrate 60 months of gains and losses and net profits of the option trading strategy using the GARCH(1,1) forecasts of S\&P 500 index with calls (Figure 6) and with puts (Figure 7 top). Figures 7 bottom illustrates the evolution of the VIX index during the 60 month-period when the strategy was implemented.

\section{Conclusion}

The objective of the paper is to validate a successful and original options trading strategy based on ARIMA $(1,1,1)$ forecasting model. It is applied to series of European call and put option contracts whose underlying asset is the S\&P 500 Composite index. The database of S\&P 500 index options involves 43,014 call and 38,784 put premiums for a total of 81,798 options traded on the CME over 60 months from January 2009 to December 2013. During this period of post-credit crisis following the bankruptcy of Lehman Brothers on September 2008 the credit was frozen, central banks implemented a zero-rate policy through quantitative easing, bond yields falling to record low forced investors to pour their money into the equity market sector propping up the S\&P 500 Composite index to historical highs.

The authors generate forecasts of the S\&P 500 composite index obtained from the ARIMA $(1,1,1)$ model. The forecasts validate a set of criteria as follows: the first criterion evaluates if the forecasted index is greater or lower than the option strike price at option maturity and the second criterion if the option premium is underpriced or overpriced at time zero. A buy or sell and hold strategy is finally implemented. This innovative trading approach based on ARIMA index forecasting is benchmarked to an equivalent approach apart that the index forecasts are obtained from $\operatorname{GARCH}(1,1)$.

The authors assess this original method of trading in terms of dollar profit (discounted net profit), profitability index, IRR when available, MIRR and the percentage of times options are correctly identified as undervalued or overvalued. The paper demonstrates the valuable contribution of this option trading strategy when trading index options. More specifically, the latter generates more profit with call than put options, as the period tested in our paper is set in a bull market, the intrinsic value of calls increasing with the index value while the intrinsic value of puts decreases. In addition, the ARIMA $(1,1,1)$ forecasting model with calls offers a higher discounted net profit than the one based on $\operatorname{GARCH}(1,1)$

Figure 6.

60 months of gains and losses of the option trading strategy of the $\operatorname{GARCH}(1,1)$ forecasting model with calls

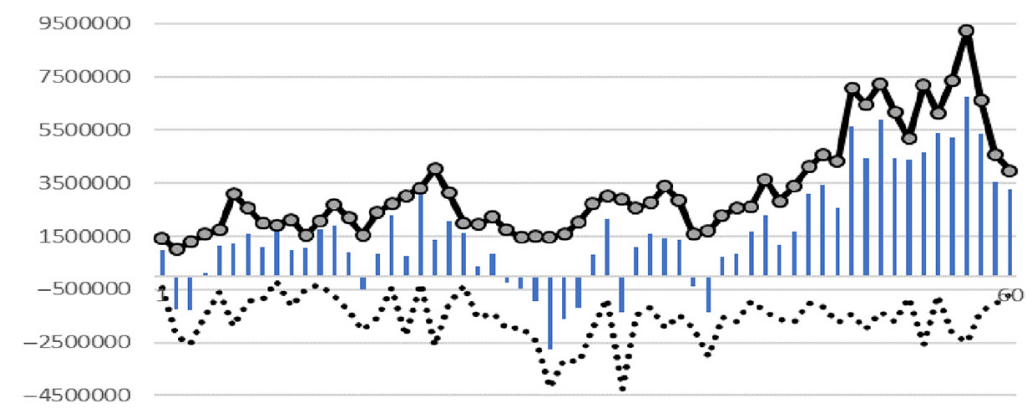

Net profit $\quad \cdots . .$. Losses $\multimap-$ Gains 


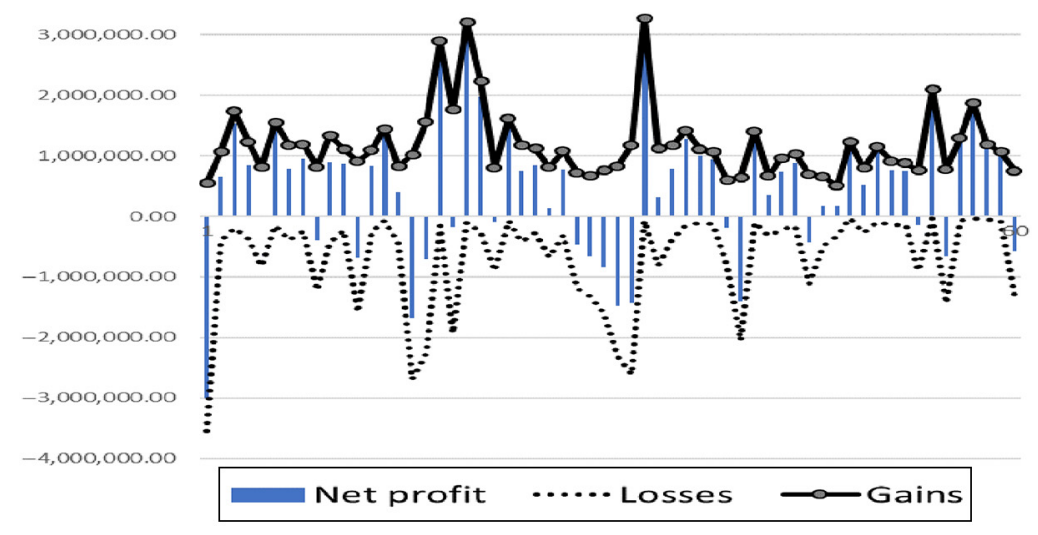

Options trading strategy

VIX index over the 60-month database

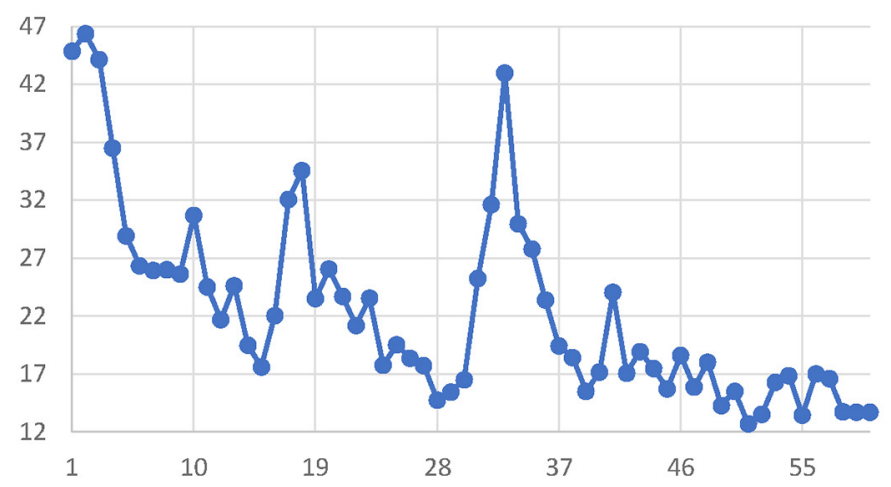

Source: Own elaboration

Figure 7. 60 months of gains and losses of the option trading strategy of the $\operatorname{GARCH}(1,1)$ forecasting model with puts (top) and VIX index (bottom)

forecasting model. In this situation, the percentage of times (out of 34,990) that the call option is correctly identified as undervalued or overvalued is $64 \%$ with ARIMA $(1,1,1)$ vs $59 \%$ with GARCH $(1,1)$. Finally, the $\operatorname{GARCH}(1,1)$ forecasting model with puts offers a higher discounted net profit than the one based on ARIMA $(1,1,1)$ forecasting model. Thus, we observe that peaks of net profits with puts correspond to peaks of volatility of the S\&P 500 Composite index represented by the VIX index. As the GARCH $(1,1)$ model incorporates a volatility component, this model is expected to provide a better forecasting accuracy than the ARIMA $(1,1,1)$ model in period of high volatility when the strategy generates higher profit.

Finally, this trading technique generates a substantial net profit when applied to a 60 -month historical database of option contracts, $\$ 97,819,217$ in terms of discounted net profit with the ARIMA $(1,1,1)$ model and calls, $\$ 23,161,345$ with the GARCH $(1,1)$ model and puts. The successful strategy over 60 months will obviously not guarantee future profits to options traders but the significant profit is such that it deserves to be 
analyzed in-depth and cross-checked under various scenarios of market and volatility. However, this paper demonstrates that the ARIMA forecasting method is a valid method for forecasting the S\&P 500 composite index and is superior to the GARCH model in the context of an application to index options trading. This finding may be confirmed by additional research.

\section{References}

Ansbacher, M. (2000), The New Options Market, 4th ed., John Wiley and Sons, New York, NY.

Bauer, R., Cosemans, M. and Eichholtz, P. (2009), "Option trading and individual investor performance", Journal of Banking and Finance, Vol. 33 No. 4, pp. 731-746, doi: 10.1016/j. jbankfin.2008.11.005.

Bittman, J. (1998), Trading Index Options, McGraw-Hill Education, New York, NY.

CBOE seminars (2017), available at: www.cboe.com/education/seminars (accessed 6 July 2019).

Chaput, J.S. and Ederington, L.H. (2003), "Option spread and combination trading”, The Journal of Derivatives, Vol. 10 No. 4, pp. 70-88, doi: 10.3905/jod.2003.319207.

Fahlenbrach, R. and Sandås, P. (2010), "Does information drive trading in option strategies?”, Journal of Banking and Finance, Vol. 34 No. 10, pp. 2370-2385, doi: 10.1016/j.jbankfin.2010.02.027.

Guo, D. (2000), "Dynamic volatility trading strategies in the currency option market", Review of Derivatives Research, Vol. 4 No. 2, pp. 133-154, doi: 10.1023/A:1009638225908.

Hemler, M. and Miller, T.W. (2013), "The performance of Options-Based investment strategies: Evidence for individual stocks during 2003-2013", The Options Clearing, available at: www. optionseducation.org/content/dam/oic/documents/literature/files/perf-options-strategies.pdf (accessed 6 July 2019).

Hong, H., Sung, H.C. and Yang, J. (2018), “On profitability of volatility trading on S\&P 500 equity index options: the role of trading frictions", International Review of Economics and Finance, Vol. 55, pp. 295-307, doi: 10.1016/j.iref.2017.07.012.

Hsieh, W. and He, H. (2014), "Informed trading, trading strategies and the information content of trading volume: evidence from the Taiwan index options market", Journal of International Financial Markets Institutions and Money, Vol. 31, pp. 187-215, doi: 10.1016/j.intfin.2014.03.012.

Hull, J.C. (2017), Options, Futures, and Other Derivatives, 10th ed., Pearson Education, Upper Saddle River, NJ.

Kraus, K. (2010), Advanced Options Trading: Approaches, Tools, and Techniques for Professionals Traders (Professional Finance and Investment), McGraw-Hill Education, New York, NY.

McMillan, L.G. (2004), McMillan on Options, 2nd ed., John Wiley and Sons, Hoboken, NJ.

Maris, K., Nikolopoulos, K., Giannelos, K. and Assimakopoulos, V. (2007), "Options trading driven by volatility directional accuracy”, Applied Economics, Vol. 39 No. 2, pp. 253-260, doi: 10.1080/ 00036840500427999 .

Montreal Exchange seminars (2017), available at: www.m-x.ca/educ_options_formation_en.php (accessed 6 July 2019).

Sheu, H. and Wei, Y. (2011), "Effective options trading strategies based on volatility forecasting recruiting investor sentiment”, Expert Systems with Applications, Vol. 38 No. 1, pp. 585-596, doi: 10.1016/j.eswa.2010.07.007.

Simon, D.P. (2017), "Trading the VIX futures roll and volatility premiums with VIX options: VIX option trading strategies", Journal of Futures Markets, Vol. 37 No. 2, pp. 184-208, doi: 10.1002/fut.21788

Simmons, P.R. (2012), "Using a differential evolutionary algorithm to test the efficient market hypothesis", Computational Economics, Vol. 40 No. 4, pp. 377-385, doi: 10.1007/s10614-0129314-2. 
Sridharan, S. (2015), "Volatility forecasting using financial statement information", The Accounting Review, Vol. 90 No. 5, pp. 2079-2106, doi: 10.2308/accr-51025.

Trester, K.R. (2003), 101 Options Trading Secrets, Institute for Options, Research Stateline, NV.

Yang, H., Kutan, A.M. and Ryu, D. (2019), "Volatility information trading in the index options market: an intraday analysis", International Review of Economics and Finance, Vol. 64, pp. 412-426, doi: 10.1016/j.iref.2019.07.006.

Corresponding author

Options trading strategy

Pierre Rostan can be contacted at: rostan.pierre@gmail.com

For instructions on how to order reprints of this article, please visit our website: www.emeraldgrouppublishing.com/licensing/reprints.htm Or contact us for further details: permissions@emeraldinsight.com 